\title{
MECHANICAL PROPERTIES AND MICROSTRUCTURAL CHARACTERISTICS OF LASER AND ELECTRON-BEAM WELDS IN V-4Cr-4Ti*
}

H. M. Chung, J.-H. Park, R. V. Strain, K. H. Leong, and D. L. Smith

Argonne National Laboratory

Argonne, IL 60439

USA
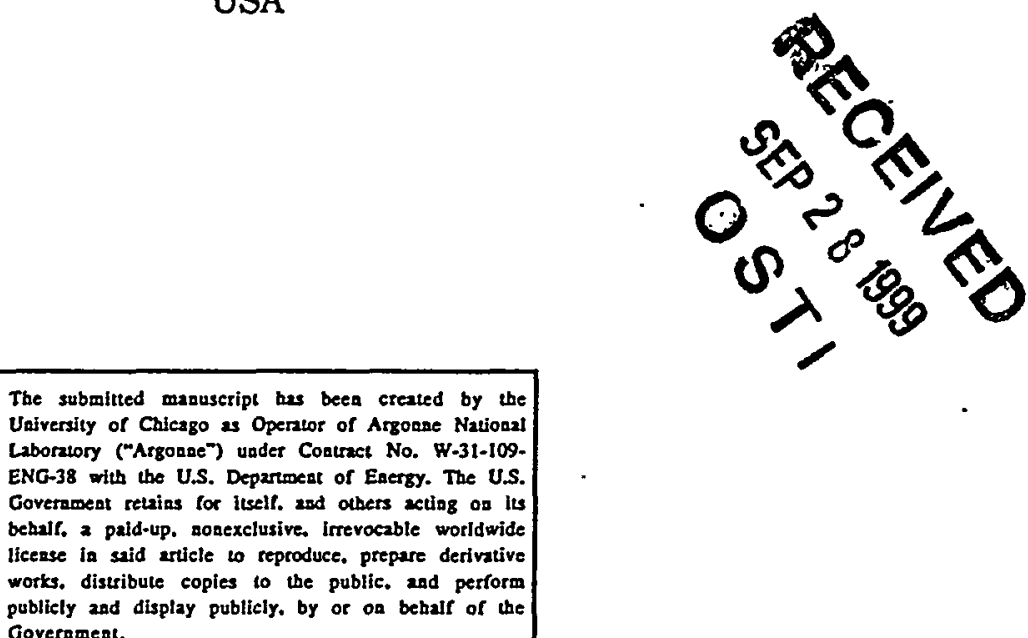

The suboltted manseript has been created by the University of Chicago as Operator of Argocae National Laboratory ("Argonae") under Coatract No. W-31-109ENG.38 with the U.S. Departocat of Energy. The U.S.

works. distribute copies to the public. and perform

Goverement.

\section{$\dot{0}$}




\section{DISCLAIMER}

This report was prepared as an account of work sponsored by an agency of the United States Government. Neither the United States Government nor any agency thereof, nor any of their employees, make any warranty, express or implied, or assumes any legal liability or responsibility for the accuracy, completeness, or usefulness of any information, apparatus, product, or process disclosed, or represents that its use would not infringe privately owned rights. Reference herein to any specific commercial product, process, or service by trade name, trademark, manufacturer, or otherwise does not necessarily constitute or imply its endorsement, recommendation, or favoring by the United States Government or any agency thereof. The views and opinions of authors expressed herein do not necessarily state or reflect those of the United States Government or any agency thereof. 


\section{DISCLAIMER}

Portions of this document may be illegible in electronic image products. Images are produced from the best available original document. 


\title{
MECHANICAL PROPERTIES AND MICROSTRUCTURAL CHARACTERISTICS OF LASER AND ELECTRON-BEAM WELDS IN V-4Cr-4Ti*
}

\author{
H. M. Chung, J.-H. Park, R. V. Strain, K. H. Leong, and D. L. Smith \\ Argonne National Laboratory, Argonne, IL 60439, U.S.A.
}

\begin{abstract}
Mechanical properties and microstructural characteristics of laser and electron-beam welds of a $500-\mathrm{kg}$ heat of $\mathrm{V}-4 \mathrm{Cr}-4 \mathrm{Ti}$ were investigated in as-welded condition and after postwelding heat treatment by impact testing, microhardness measurement, optical microscopy, $\mathrm{X}$-ray diffraction, and transmission electron microscopy (TEM). Ductile-brittle transition temperatures of the laser and electron-beam welds were significantly higher than that of the base metal. However, excellent impact properties could be restored in both types of welds by postwelding annealing at $1000^{\circ} \mathrm{C}$ for $1 \mathrm{~h}$ in vacuum. Analysis by TEM revealed that annealed weld zones were characterized by extensive networks of fine $V(C, O, N)$ precipitates, which clean away $\mathrm{O}, \mathrm{C}$, and $\mathrm{N}$ interstitials from the grain matrices. This process is accompanied by simultaneous annealing-out of the dense dislocations present in the weld zone. This finding could be useful in identifying an optimal welding procedure by controlling and adjusting the cooling rate of the weld zone by an innovative method to maximize the precipitation of $\mathrm{V}(\mathrm{C}, \mathrm{O}, \mathrm{N})$.
\end{abstract}

KEY WORDS: $\quad \mathrm{V}-4 \mathrm{Cr}-4 \mathrm{Ti}$ weld, impact properties, postwelding annealing, $\mathrm{V}(\mathrm{C}, \mathrm{O}, \mathrm{N})$

\section{INTRODUCTION}

Recent research in vanadium alloys has focused on development of welding procedures and weld properties of the reference alloy $\mathrm{V}-4 \mathrm{Cr}-4 \mathrm{Ti}$. A program is being conducted to develop an optimal laser welding procedure that can be applied to welding of magnetic fusion reactor structural components to be fabricated from vanadium alloy(s). Laser welds were produced on $3.8-\mathrm{mm}$-thick plates of a $500-\mathrm{kg}$ heat of $\mathrm{V}-4 \mathrm{Cr}-4 \mathrm{Ti}$, and mechanical properties and microstructural characteristics were investigated by several techniques in the present study. To complement the primary studies on laser welds, electron-beam (EB) welds were also investigated. In this paper, we report results of investigation of impact properties and hardening behavior of the laser and $\mathrm{EB}$ welds in the production-scale heat of $\mathrm{V}-4 \mathrm{Cr}-4 \mathrm{Ti}$ in aswelded condition and after postwelding heat-treatment (PWHT) at $\approx 1000^{\circ} \mathrm{C}$ for $1 \mathrm{~h}$ in high vacuum. To provide an understanding of the mechanical properties, microstructural characteristics were also investigated by X-ray diffraction, transmission electron microscopy (TEM), and chemical analysis on as-welded and postwelding-annealed specimens.

\section{EXPERIMENTAL PROCEDURES}

Compositions of the raw vanadium ingot and the V-4Cr-4Ti alloy (500-kg Heat \#832665) are given in Table 1. The extruded plate was rolled and annealed several times to produce 3.8$\mathrm{mm}$-thick plates that were then annealed in the factory for $\approx 2 \mathrm{~h}$ at a nominal temperature between 1050 and $1070^{\circ} \mathrm{C}$ in a diffusion-pumped vacuum furnace. The bead-on-plate laser weld was produced in air with an argon-gas purge and a $6-\mathrm{kW}$ continuous $\mathrm{CO}_{2}$ laser at a welding speed of $\approx 45 \mathrm{~mm} / \mathrm{s}$. Details of this procedure are reported elsewhere. 1 One-third-size Charpy impact specimens $\left(3.3 \times 3.3 \times 25.4 \mathrm{~mm}, 30^{\circ}\right.$ notch angle, and $0.61-\mathrm{mm}$ notch depth) were machined from the welded plate. The L-S orientation of the impact specimens is shown

"Work supported by the U.S. Department of Energy, Office of Fusion Energy, under Contract W-31-109-Eng-38. 
schematically in Fig. 1. Direction of crack propagation was perpendicular to the rolling direction and the flat surface of the plate. As shown, a V-notch was located in the center of the weld zone so that the crack would propagate entirely within the weld zone. The Charpy specimens machined from the weld were subjected to the customary degassing treatment at $400^{\circ} \mathrm{C}$ for $1 \mathrm{~h}$ in ion-pumped vacuum to expel hydrogen. This state of the material is referred to as the "as-welded" condition. Some of the specimens were annealed instead at $1000^{\circ} \mathrm{C}$ for 1 $h$ in ion-pumped vacuum, resulting in the "postwelding heat-treated" condition. Following impact testing at -100 to $+300^{\circ} \mathrm{C}$, fractographic analysis and microhardness measurement were conducted on broken or bent pieces of the Charpy specimen. Vickers microhardness was measured with a 25-g load near the fracture region on one side of the Charpy specimen.

Table 1. Chemical composition (impurities in wppm) of industrial-scale (500 kg) heat of V$4 \mathrm{Cr}-4 \mathrm{Ti}^{\mathrm{a}}$ and $\mathrm{V}$ raw stock used to melt the ingot.

\begin{tabular}{cccccccccccccccccc}
\hline Heat ID & Material & $\mathrm{Cr}$ & $\mathrm{TI}$ & $\mathrm{Al}$ & $\mathrm{Fe}$ & $\mathrm{Mo}$ & $\mathrm{Nb}$ & $\mathrm{Cu}$ & $\mathrm{Si}$ & $\mathrm{O}$ & $\mathrm{N}$ & $\mathrm{C}$ & $\mathrm{S}$ & $\mathrm{P}$ & $\mathrm{Ca}$ & $\mathrm{Cl}$ & $\mathrm{B}$ \\
\hline 820630 & raw & $<100$ & $<50$ & 100 & 230 & 410 & $<50$ & $<50$ & 800 & 200 & 62 & 75 & 10 & $<30$ & - & $<2$ & $<5$ \\
832665 & alloy & $3.75 \%$ & $4.16 \%$ & 180 & 180 & 330 & $<50$ & $<50$ & 790 & 280 & 82 & 64 & $<10$ & $<30$ & $<10$ & $<2$ & 7 \\
& & $3.72 \%$ & $3.79 \%$ & 190 & 220 & 350 & 50 & $<50$ & 840 & 360 & 80 & 80 & $<10$ & $<30$ & $<10$ & $<2$ & $<5$ \\
& & $3.83 \%$ & $3.80 \%$ & 105 & 270 & 260 & $<50$ & $<50$ & 720 & 290 & 93 & 94 & $<10$ & $<30$ & $<10$ & $<2$ & $<5$ \\
\hline
\end{tabular}

apetermined from three different positions in the 64-mm-thick and 200-mm-wide extruded bar.

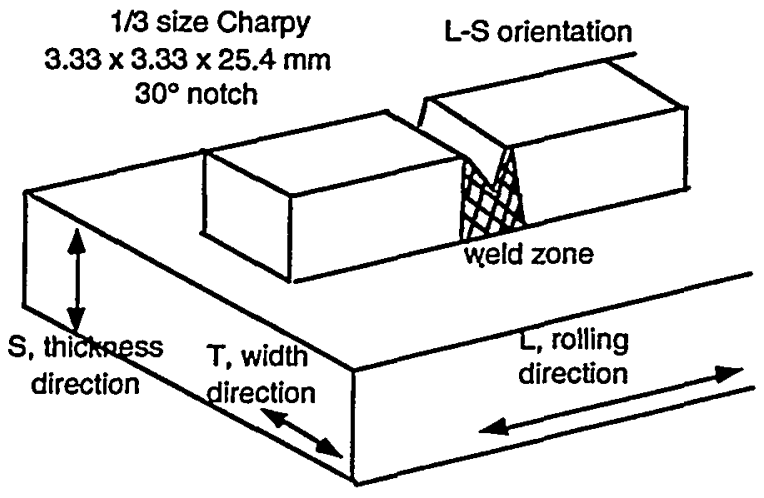

Fig. 1 .

Orientation of Charpy impact specimens of laser and $E B$ welds of $\mathrm{V}-4 \mathrm{Cr}-4 \mathrm{Ti}$

\section{IMPACT PROPERTIES AND HARDNENING BEHAVIOR}

Impact properties of the laser and $\mathrm{EB}$ welds measured at -100 to $300^{\circ} \mathrm{C}$ are shown in Fig. 2; included for comparison are weld impact energies measured after degassing the machined Charpy specimens at $400^{\circ} \mathrm{C}$ (referred to as "as-weided" condition) and at $1000^{\circ} \mathrm{C}$ ("PWHT" condition). Impact energy of the base metal is also plotted in the figure as a function of temperature. The ductile-brittle-transition temperatures (DBTTs) of the laser and EB welds were $\approx 80^{\circ} \mathrm{C}$ and $\approx 30^{\circ} \mathrm{C}$, respectively. These are significantly higher than the DBTT of the base metal $\left(\approx-170^{\circ} \mathrm{C}\right)$. However, excellent impact properties with DBTTs $<-80^{\circ} \mathrm{C}$ could be restored in both the laser and $\mathrm{EB}$ welds by postwelding annealing at $1000^{\circ} \mathrm{C}$ for $1 \mathrm{~h}$. Impact energies at $<-80^{\circ} \mathrm{C}$ could not be measured because a sufficient number of specimens were not available. True DBTTs of the postwelding annealed laser and EB welds are probably as low as the DBTT of the base metal.

Consistent with the effects of PWHT on impact properties, the microhardness of the laser and EB welds decreased significantly after postwelding annealing. This is shown in Fig. 3. Vickers hardnesses of the fusion and heat-affected zones (HAZ) of the laser and EB welds were $\approx 200$ and $\approx 170$, respectively, in "as-welded" condition. After the postwelding annealing, hardness decreased to $\approx 130$. Hardness of the base metal decreased from $\approx 160$ to $\approx 130$ after the postwelding annealing. As expected, absorbed impact energy of the laser or EB welds seems 
to be more sensitive to postwelding annealing at $1000^{\circ} \mathrm{C}$ than hardness. To understand the PWHT behavior, microstructural characteristics were then investigated by several metallographic techniques.
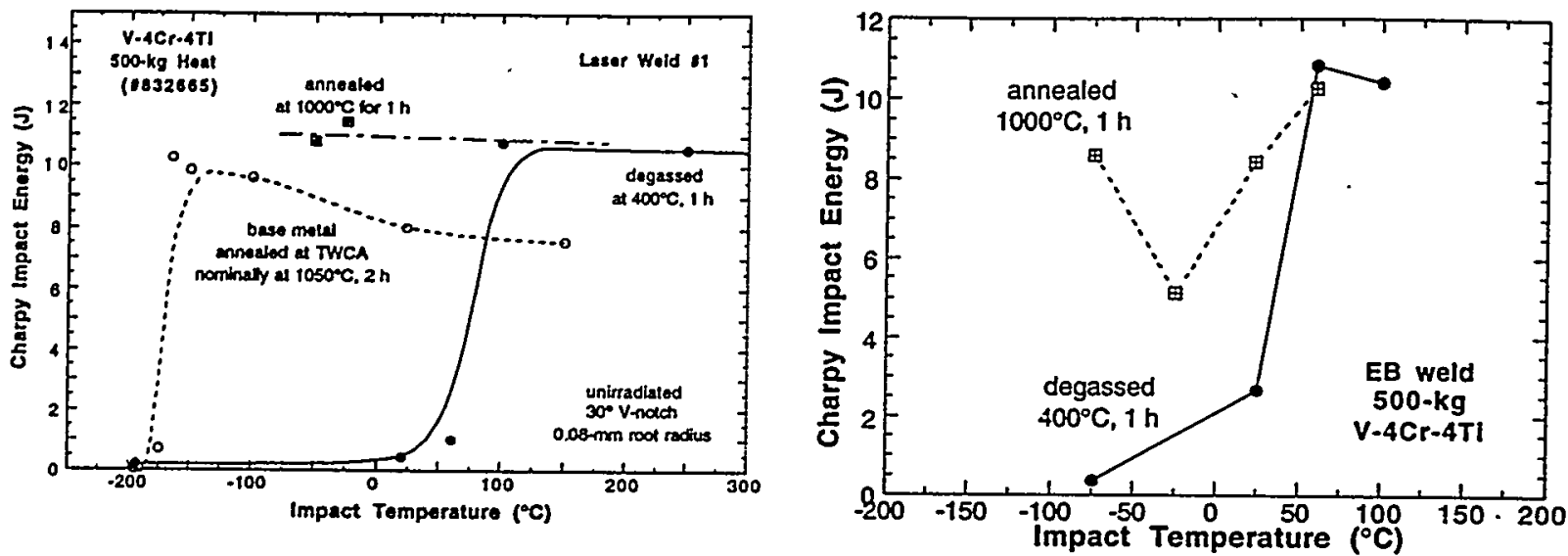

Fig. 2. Impact properties of laser (left) and electron-beam (right) welds of $V$ $4 \mathrm{Cr}-4 \mathrm{Ti}$ after annealing under various conditions.
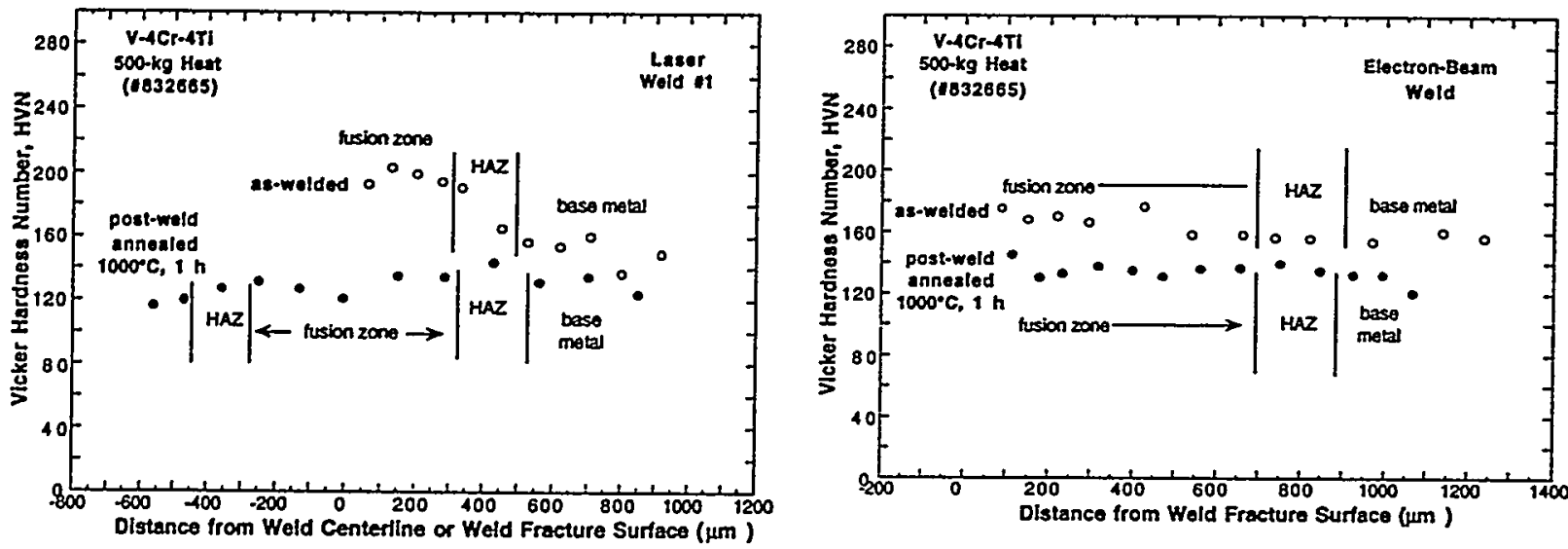

Fig. 3. Hardness profiles of laser (left) and electron-beam (right) welds of $V-4 \mathrm{Cr}-4 \mathrm{Ti}$ before and after annealing at $1000^{\circ} \mathrm{C}$.

\section{MICROSTRUCTURAL ANALYSES}

\section{Optical Microscopy}

Optical micrographs of the as-welded and postwelding-annealed specimens of the laser weld are shown in Fig. 4. The photomicrographs were obtained from the side of the broken or bent Charpy specimens that were impact-tested after the heat treatment. In the photomicrograph of the postwelding-annealed material, a characteristic fine substructure is visible within the elongated grains of the fusion zone. This substructure is absent in the as-welded material. In EB welds, early-stage development of the similar fine substructure was observed even in aswelded material (Fig. 5). In the postwelding-annealed EB weld, the substructure appears to have developed into an advanced stage.

\section{Chemical Analysis}

Concentrations of $\mathrm{O}, \mathrm{C}$, and $\mathrm{N}$ were analyzed in EB welds. Three specimens of base metal and three specimens of EB weld were analyzed. The concentrations were compared in Table 2 with 

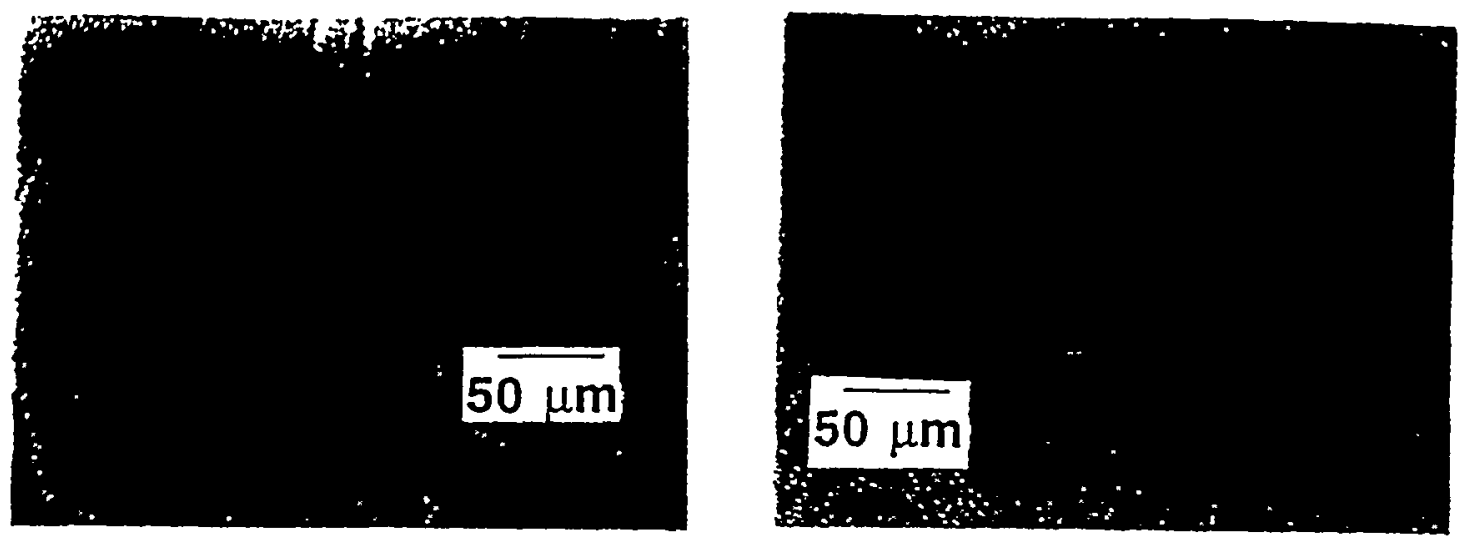

Fig. 4. Optical metallographs of laser weld of V-4Cr-4Ti in as-welded state (left) and after postwelding annealing at $1000^{\circ} \mathrm{C}$ for $1 \mathrm{~h}$ (right).
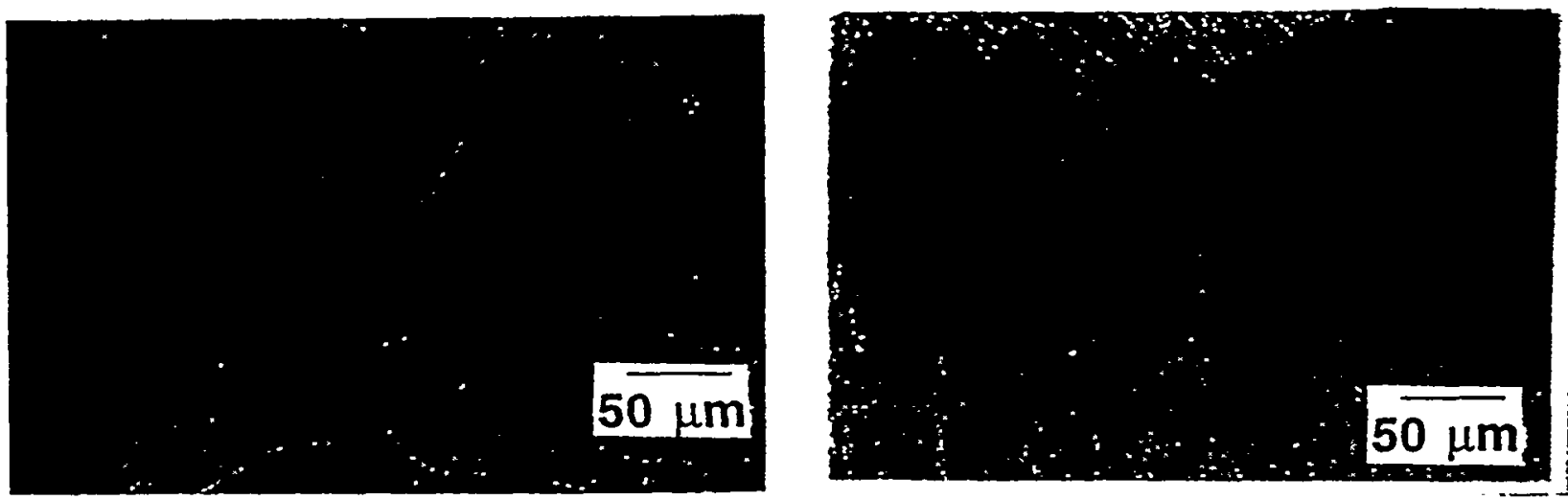

Fig. 5. Optical metallographs of electron-beam weld of $\mathrm{V}-4 \mathrm{Cr}-4 \mathrm{Ti}$ in as-welded state (left) and after postwelding annealing at $1000^{\circ} \mathrm{C}$ for $1 \mathrm{~h}$ (right).

with those measured on an extruded plate $(64 \mathrm{~mm}$ thick) and a rolled base-metal plate ( 3.8 $\mathrm{mm}$ thick). Compared to the composition of the rolled and annealed base-metal plate, the increase in $\mathrm{O}, \mathrm{N}$, and $\mathrm{C}$ in the EB welds was insignificant. Therefore, contamination by $\mathrm{O}, \mathrm{N}$, and $C$ in the EB and laser welds appears to be at best a secondary factor in the large shifts in DBTT before and after welding.

Table 2. Impurity concentration (in wppm) in 500-kg V-4Cr-4Ti Heat \#832665 after extrusion, rolling and annealing, and electron-beam welding

\begin{tabular}{|c|c|c|c|c|c|c|}
\hline \multirow{2}{*}{$\begin{array}{c}\text { Fabricated } \\
\text { Material }\end{array}$} & \multicolumn{2}{|l|}{0} & \multicolumn{2}{|c|}{$\mathrm{N}$} & \multicolumn{2}{|l|}{$\mathrm{C}$} \\
\hline & reading & average & reading & average & reading & average \\
\hline Extruded plate & 310 & 310 & 85 & 85 & 80 & 80 \\
\hline Rolled Plate & $450,480,467$ & 466 & $25,28,30$ & 27 & $300,230,240$ & 257 \\
\hline EB weld & $510,520,520$ & 517 & $30,25,29$ & 28 & $240,270,240$ & 250 \\
\hline
\end{tabular}

\section{X-Ray Diffraction Analvsis}

Tetragonal distortion was suspected initially in the crystallographic structure of the elongated grains in the fast-cooled fusion zone. However, X-ray diffraction analysis showed no evidence of tetragonal distortion; only the diffraction peaks that correspond to the bcc structure of vanadium were present, i.e., (110), (200), (211), (220), and (310). However, the lattice constant of the weld fusion zone was found to be $\approx 0.13 \%$ larger than that of the base metal, i.e., 0.30315 vs. $0.30275 \mathrm{~nm}$, respectively. These lattice constants were then used to index the TEM diffraction patterns. 


\section{TEM Analysis}

As-welded microstructures of laser and EB welds were characterized by dense dislocations as shown in Fig. 6. Ti $(O, N, C)$ precipitates normally present in extruded, rolled. and annealed plates were conspicuously absent, showing that they had dissolved during welding. Reprecipitation of Ti(O,N,C) during cool-down of the weld zone was negligible. Postweldingannealed laser and EB welds were characterized by an extensive network of precipitates that were not observed in the base metals of any vanadium alloys investigated in this program. Examples of the network precipitate structures are shown in Fig. 7 for both laser and EB welds. Individual precipitates were typically rodlike in shape, $200-500 \mathrm{~nm}$ in length, and $\approx 50-$ $100 \mathrm{~nm}$ in diameter. The rodlike morphology indicates that the precipitates are not $\mathrm{Ti}(\mathrm{O}, \mathrm{N}, \mathrm{C})$, which is usually spherical or ellipsoidal and 300-500 $\mathrm{nm}$ in diameter. The morphologies shown in Fig. 7 indicate that the precipitates in the laser and EB welds are of the same type.
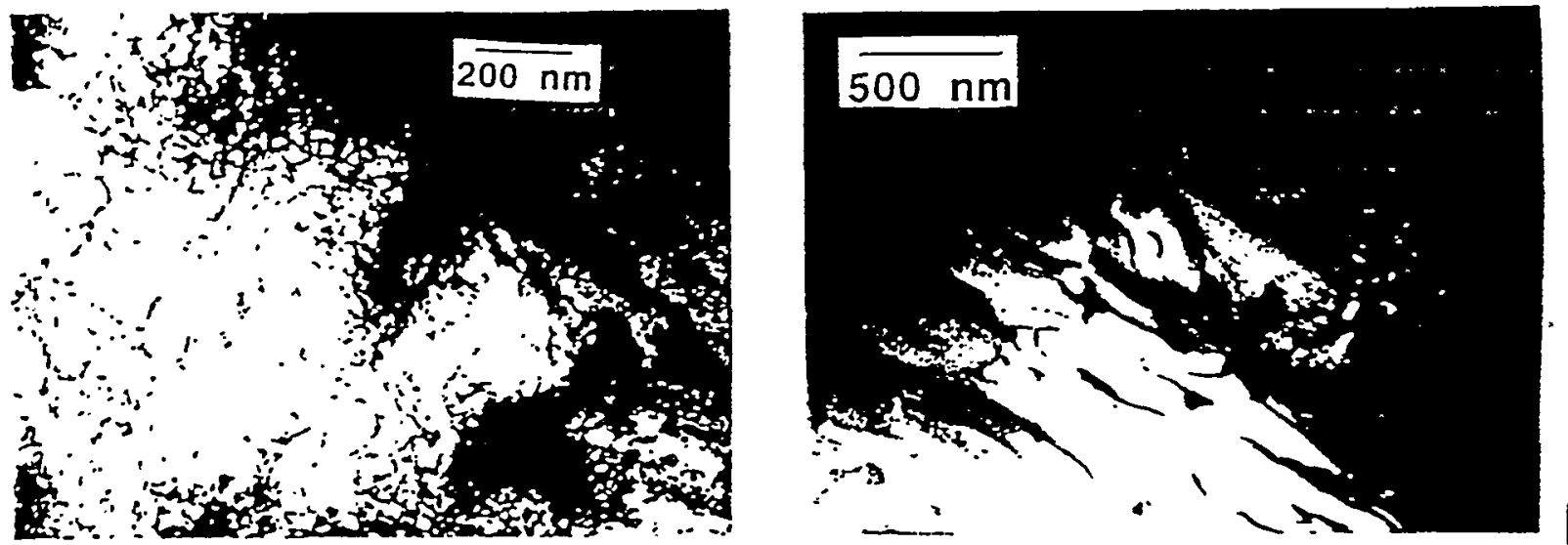

Fig. 6. TEM bright-field photomicrographs of laser $(A)$ and $E B(B)$ welds of $V-4 C r-4 T i$ before postwelding annealing. Note dense dislocations and absence of $T i(O, N, C)$.
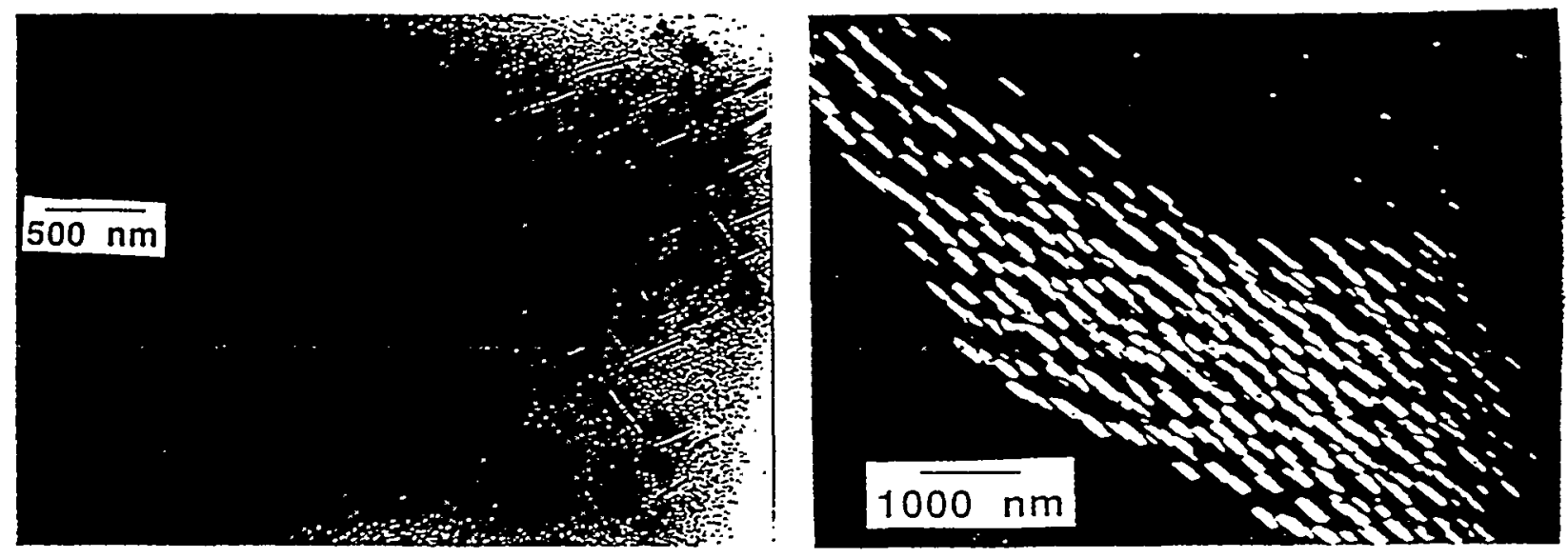

Fig. 7. Dense precipitate substructure in fusion zone of laser (left, bright-field image) and electron-beam (right, dark-field image) welds of $\mathrm{V}-4 \mathrm{Cr}-4 \mathrm{Ti}$ after postivelding annealing at $1000^{\circ} \mathrm{C}$ for $1 \mathrm{~h}$. Note absence of dislocations and Ti(O,N,C).

To obtain a clue as to the nature of the precipitates, selected precipitates were analyzed by energy-dispersive spectroscopy (EDS). A few precipitates located at the edge of the hole of the perforated TEM foil were analyzed. The measured EDS spectrum, therefore, consisted of Xrays that originated predominantly from the precipitate, while X-rays from the alloy matrix were in minor proportion. Results of the EDS analysis of the precipitate and alloy matrix, given in Table 3 , indicate that the precipitate has high concentrations of $\mathrm{V}, \mathrm{C}$, and $\mathrm{O}$, and, to a lesser extent, Ti. The nitrogen signal was negligible. 
Table 3. Summary of EDS analysis of composition (at.\%) of characteristic precipitates in laser weld fusion zone after postwelding annealing at $1000^{\circ} \mathrm{C}$ for $1 \mathrm{~h}$ in vacuum.

\begin{tabular}{cccccc}
\hline Material & $\mathrm{V}$ & $\mathrm{Ti}$ & $\mathrm{Cr}$ & $\mathrm{C}$ & $\mathrm{O}$ \\
\hline Matrix & 92.55 & 3.68 & 3.77 & - & - \\
Precipitate & 16.72 & 5.94 & 0.76 & 66.99 & 9.59 \\
\hline
\end{tabular}

However, exact compositions of $\mathrm{C}$ and $\mathrm{O}$ in this type of analysis must be considered as only qualitative, because contamination of $\mathrm{C}$ from the TEM vacuum chamber and hydrocarbon thinning solution is possible. Furthermore, accurate determination of $C$ and $O$ by EDS is complicated because the weak $K$ lines of $C$ and $O$ nearly overlap the $L$ lines of $V$ and $T i$. Therefore, exact identification of the precipitate phase must be verified by a more precise analysis through dark-field imaging and indexing selected-area diffraction patterns (SADPs). Systematic analysis of dark-field images and SADPs showed that the characteristic precipitates are $V(C, O),{ }^{2}$ which is an fcc phase with a lattice constant of $0.419 \mathrm{~nm}$. An example of the indexed diffraction patterns is shown in Fig. 8. In this pattern, one zone axis of vanadium and two zone axes of $\mathrm{V}(\mathrm{C}, \mathrm{O})$ phase are operating. Indexed diffraction patterns obtained from the laser and EB welds showed that the precipitates formed in the two types of welds are the same $V(C, O)$ phase. It must be emphasized that the precipitate SADPs could be indexed exactly only on the basis of the structure of $V(C, O)$, but by no means could they be indexed on the basis of the structure of $\mathrm{Ti}(\mathrm{O}, \mathrm{N}, \mathrm{C})^{3}$ even though the precipitates appear to contain small amount of $\mathrm{Ti}$.

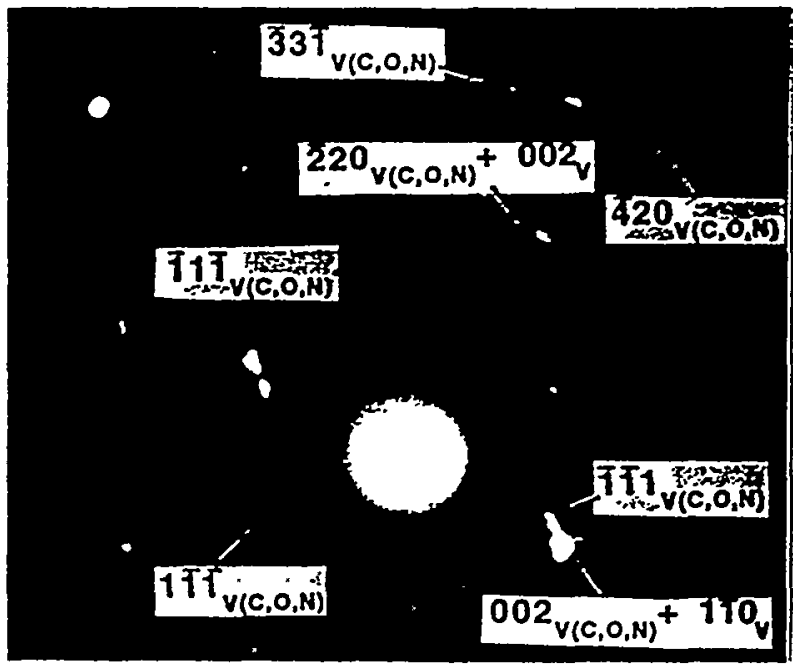

Fig. 8.

Indexed selected area diffraction pattern of laser weld fusion zone of $\mathrm{V}-4 \mathrm{Cr}-4 \mathrm{Ti}$ postwelding-annealed at $1000^{\circ} \mathrm{C}$ for $1 \mathrm{~h}$.

\section{DISCUSSION}

VC (lattice constant $0.417 \mathrm{~nm})$, VO $(0.409 \mathrm{~nm})$, and VN $(0.413 \mathrm{~nm})$ phases are isostructural (fcc, $\mathrm{Na}-\mathrm{Cl}$ type) and have similar lattice constants ${ }^{2}$ and high miscibility with one another. ${ }^{4}$ This is similar to the characteristics of $\mathrm{TiC}, \mathrm{TiO}$, and $\mathrm{TiN}$, which are also isostructural fcc with similar lattice constants and high miscibility. Therefore, as for $T i(C, O, N)$, the vanadium-base precipitates characteristically contained in the postwelding-annealed welds are believed to be in the chemical form of $\mathrm{V}(\mathrm{C}, \mathrm{O}, \mathrm{N})$, with variable proportions of $\mathrm{C}, \mathrm{O}$, and $\mathrm{N}$ in the precipitate. However, for the precipitate analyzed in Table 3, $\mathrm{N}$ content was negligible. The substructures observed in the low-magnification optical photomicrographs of Figs. 4 and 5 are indeed the same as the precipitate network shown in the high-magnification TEM photomicrographs of Fig. 7.

Vanadium-base precipitates have been observed only rarely in $\mathrm{V}$ - $\mathrm{Ti}$ or $\mathrm{V}-\mathrm{Cr}-\mathrm{Ti}$ alloys. $5-7$ In the Ti-containing binary or ternary alloys of vanadium, observed precipitates are usually Ti-based phases, such as titanium oxycarbonitrides, titanium sulfides, or titanium phosphides. 5 
Vanadium-base precipitates were observed only in alloys containing high levels of unusual impurities such as $\mathrm{Cl}, \mathrm{Ca}$, and $\mathrm{Li}$, i.e., vanadium oxychlorides in $\mathrm{V}-5 \mathrm{Cr}-5 \mathrm{Ti}$, which was melted with low-quality sponge $\mathrm{Ti}^{6}$ and $\mathrm{Ca}$-vanadate in unalloyed vanadium produced by the calciareduction process. ${ }^{6}$ In an irradiated V-20Ti alloy which contained high boron, Li-vanadate was also observed. ${ }^{7}$ As pointed out previously, from the thermodynamic standpoint, the precipitation of vanadium oxychlorides or calcium vanadates is preferred over precipitation of Ti-based precipitates in $\mathrm{Cl}$ - or $\mathrm{Ca}$-rich alloys containing a certain level of oxygen. ${ }^{6}$

Precipitation of $\mathrm{V}(\mathrm{C}, \mathrm{O}, \mathrm{N})$ seems to be preferred over precipitation of $\mathrm{Ti}(\mathrm{C}, \mathrm{O}, \mathrm{N})$ in a metastable structure such as the weld fusion zone. Following dissolution of Ti $(O, N, C)$ during melting, a laser or EB weld fusion zone contains dense dislocations and higher levels of $\mathrm{O}, \mathrm{N}$, and $\mathrm{C}$ as interstitials in the grain matrices. It appears then that a dense dislocation structure plays an essential role in the precipitation of $V(C, O, N)$ in the welds. The network-like distribution of clusters of the $V(C, O, N)$ precipitates shown in Fig. 7 seems to support this premise. Under the same annealing condition at $1000^{\circ} \mathrm{C}$ for $1 \mathrm{~h}$ in high vacuum, $\mathrm{V}(\mathrm{C}, \mathrm{O}, \mathrm{N})$ precipitates were not observed in the factory-annealed base metal, which is relatively free of dislocations and contains the normal $\mathrm{Ti}(\mathrm{O}, \mathrm{N}, \mathrm{C})$ precipitates. This seems to be additional evidence that highdensity dislocations play an important role in the precipitation of $(\mathrm{V}(\mathrm{C}, \mathrm{N}, \mathrm{O})$ in the welds during postwelding-annealing.

It seems evident that the drastic improvement in impact toughness is a result of the simultaneous process of profuse formation of $\mathrm{V}(\mathrm{C}, \mathrm{O}, \mathrm{N})$ precipitates and annealing-out of the dense dislocations that occurs in the weld zone during the postwelding annealing. The combined process seems to make grain matrices that are very low in $O, C$, and $N$ and virtually free of dislocations and residual stress. Crack propagation through this type of microstructure would then be very difficult, which leads to excellent impact toughness.

The precipitation kinetics of $\mathrm{V}(\mathrm{C}, \mathrm{O}, \mathrm{N})$ in the metastable structure of laser welds are believed to be strongly influenced by annealing temperature. Therefore, identification of the temperature of fastest precipitation kinetics in the time-temperature-transformation (TTT) curve will be important. This temperature is probably significantly higher than $1000^{\circ} \mathrm{C}$, and the kinetics at that temperature seem to be fast. This can be deduced from the observation of the early-stage development of the precipitate network in EB welds even without postwelding annealing (Fig. 5). A controlled cooling of a laser weld would then be an attractive idea to improve welding procedures and properties, in which the weld structure remains at the temperature of maximum precipitation kinetics for a reasonable period of time to allow development of networks of $V(C, O, N)$ precipitates.

\section{CONCLUSIONS}

1. Hardening behavior and impact properties of laser and electron-beam welds of $\mathrm{V}-4 \mathrm{Cr}-4 \mathrm{Ti}$ were investigated with and without postwelding annealing at $1000^{\circ} \mathrm{C}$ for $1 \mathrm{~h}$ in high vacuum. Ductile-brittle transition temperatures (DBTTs) of the laser and electron-beam welds were $=80^{\circ} \mathrm{C}$ and $\approx 30^{\circ} \mathrm{C}$, respectively, significantly higher than the DBTT of the base metal. However, excellent impact properties could be restored in both the laser and electron-beam welds by postwelding annealing at $1000^{\circ} \mathrm{C}$ for $1 \mathrm{~h}$ in vacuum. Consistent with this, microhardness of the laser and EB welds decreased significantly following postwelding annealing.

2. Postwelding-annealed welds were characterized by extensive formation of networks of fine $\mathrm{V}(\mathrm{C}, \mathrm{O}, \mathrm{N})$ precipitates. This process occurs with simultaneous annealing-out of the dense dislocations present in the metastable fusion zone.

3. The drastic improvement in impact toughness is a result of this simultaneous process, which occurs in the fusion zone during the postwelding annealing at $1000^{\circ} \mathrm{C}$ for $1 \mathrm{~h}$. The combined process seems to make grain matrices that are very low in $O, C$, and $N$ and virtually free of dislocations and residual stress. Resistance to crack propagation through 
the grains of this type of microstructure is high, and as a result, excellent impact toughness is produced.

4. The precipitation kinetics of $\mathrm{V}(\mathrm{C}, \mathrm{O}, \mathrm{N})$ in the metastable structure of laser welds are predicted to be strongly influenced by annealing temperature, and hence by cooling history. Therefore, it seems possible to produce high-quality welds under practical conditions by controlling and adjusting the cooling rate of the weld fusion zone through some innovative method to maximize the precipitation of $\mathrm{V}(\mathrm{C}, \mathrm{O}, \mathrm{N})$.

\section{ACKNOWLEDGMENT}

The authors thank L. J. Nowicki and K. Fukumoto for extensive experimental contributions and examination of TEM specimens, respectively.

\section{REFERENCES}

1. R. V. Strain, K. H. Leong, and D. L. Smith, "Development of Laser Welding Techniques of Vanadium Alloys," in Fusion Reactor Materials, Semiannual Prog. Rep. DOE/ER-0313/19, Oak Ridge National Laboratory, Oak Ridge, TN (1995), pp. 3-4.

2. M. Hansen, Constitution of Binary Alloys, 2nd Ed., McGraw-Hill, New York, 1958.

3. H. M. Chung and D. L. Smith, J. Nucl. Mater. 191-194 (1992) 942.

4. C. K. Gupta and N. Krishnamurthy, Extractive Metallurgy of Vanadium, Elsevier, Amsterdam, 1992.

5. H. M. Chung, B. A. Loomis, and D. L. Smith, in Effects of Radiation in Metals: 16th Intl. Symp., ASTM STP 1175, D. S. Gelles, R. K. Nanstad, and T. A. Little, eds., American Society for Testing and Materials, Philadelphia, 1993, pp. 1185-1120.

6. H. M. Chung, J. Gazda, L. J. Nowicki, J. E. Sanecki, and D. L. Smith, in USDOE Fusion Reactor Materials Semiannual Report, DOE/ER-0313/15, 1994, pp. 207-218.

7. H. M. Chung, B. A. Loomis, D. L. Smith, J. Nucl. Mater. 212-215 (1994) 804. 